STRUCTURAL

BIOLOGY
Received 9 December 2015

Accepted 9 December 2015

Keywords: L-asparaginase; Pyrococcus furiosus; linker-less assembly; corrigendum

\section{Structural and functional insights into an archaeal L-asparaginase obtained through the linker-less assembly of constituent domains. Corrigendum}

\section{Rachana Tomar, ${ }^{\text {a }}$ Pankaj Sharma, ${ }^{\mathrm{b}} ¥$ Ankit Srivastava, ${ }^{\mathrm{a}}$ Saurabh Bansal, ${ }^{\mathrm{a}}$ Ashish ${ }^{\mathrm{b}}$ and Bishwajit Kundu ${ }^{\mathrm{a} *}$}

${ }^{\mathbf{a}}$ Kusuma School of Biological Sciences, Indian Institute of Technology Delhi, New Delhi, India, and ${ }^{\mathbf{b}}$ CSIR - Institute of Microbial Technology, Chandigarh, India. *Correspondence e-mail: bkundu@bioschool.iitd.ac.in

A correction is made to Fig. 7 in the article by Tomar et al. [(2014). Acta Cryst. D70, 3187-3197].

In the article by Tomar et al. (2014), the product formula in Fig. 7 was incorrect. A new version of the figure with the correct formula is given here.

\section{References}

Tomar, R., Sharma, P., Srivastava, A., Bansal, S., Ashish, \& Kundu, B. (2014). Acta Cryst. D70, 3187-3197.

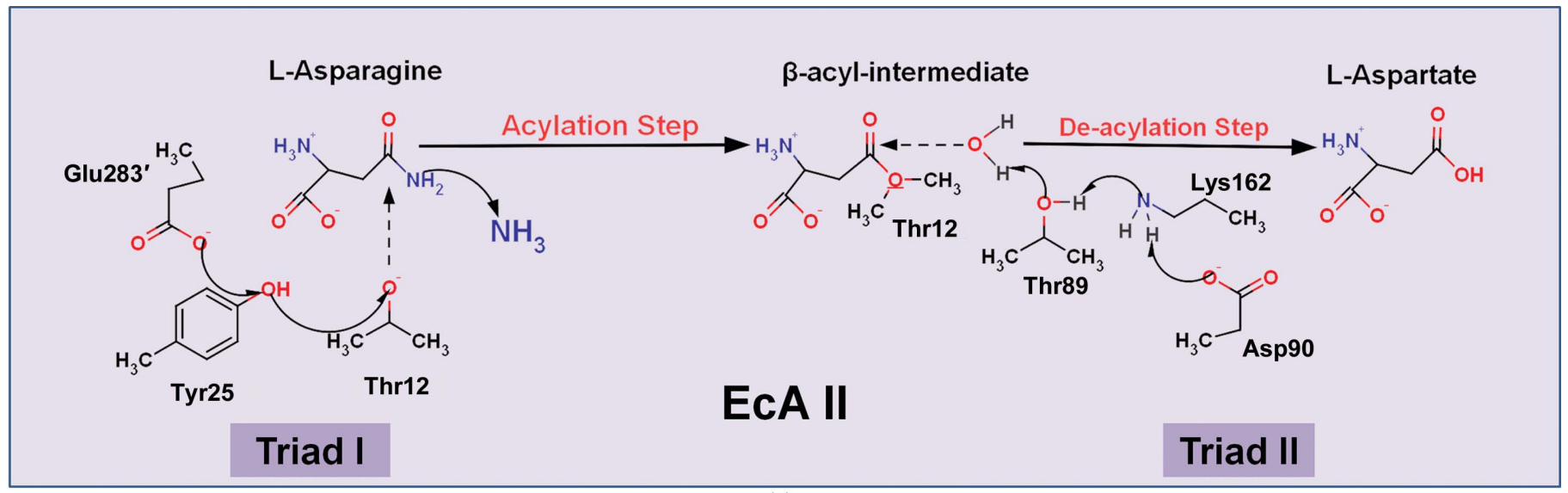

(a)

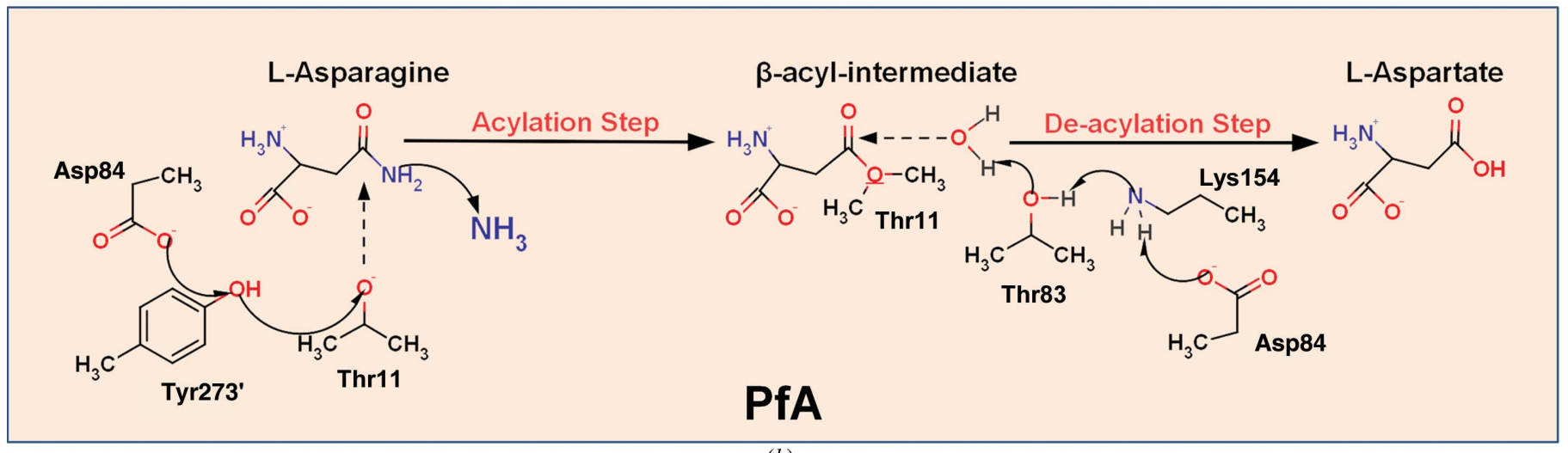

Figure 7

(b)

Reaction mechanism at the EcAII ( $a$ ) and PfA $(b)$ catalytic triads. A common acidic residue Asp84 is present in both triads I and II of PfA, with Tyr273' in triad I as the basic residue. 